\title{
The case for a 3rd generation supraglottic airway device facilitating direct vision placement
}

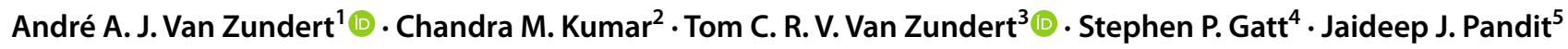

Received: 11 May 2020 / Accepted: 25 May 2020 / Published online: 15 June 2020

(c) Springer Nature B.V. 2020

\begin{abstract}
Although 1st and 2nd generation supraglottic airway devices (SADs) have many desirable features, they are nevertheless inserted in a similar 'blind' way as their 1st generation predecessors. Clinicians mostly still rely entirely on subjective indirect assessments to estimate correct placement which supposedly ensures a tight seal. Malpositioning and potential airway compromise occurs in more than half of placements. Vision-guided insertion can improve placement. In this article we propose the development of a 3rd generation supraglottic airway device, equipped with cameras and fiberoptic illumination, to visualise insertion of the device, enable immediate manoeuvres to optimise SAD position, verify whether correct 1st and 2nd seals are achieved and check whether size selected is appropriate. We do not provide technical details of such a '3rd generation' device, but rather present a theoretical analysis of its desirable properties, which are essential to overcome the remaining limitations of current 1 st and 2 nd generation devices. We also recommend that this further milestone improvement, i.e. ability to place the SAD accurately under direct vision, be eligible for the moniker '3rd generation'. Blind insertion of SADs should become the exception and we anticipate, as in other domains such as central venous cannulation and nerve block insertions, vision-guided placement becoming the gold standard.
\end{abstract}

Keywords Anaesthesia $\cdot$ Supraglottic airway device $\cdot$ Complications $\cdot$ Positioning $\cdot$ COVID-19

Tom C. R. V. Van Zundert

tomvanzundert@icloud.com

André A. J. Van Zundert

vanzundertandre@gmail.com

Chandra M. Kumar

chandra.kumar2406@gmail.com

Stephen P. Gatt

gattsp@gmail.com

Jaideep J. Pandit

jaideep.pandit@sjc.ox.ac.uk

1 Department of Anaesthesia and Perioperative Medicine, Royal Brisbane \& Women's Hospital, The University of Queensland, Brisbane, QLD, Australia

2 Department of Anaesthesia, Khoo Teck Puat Hospital, Singapore, Singapore

3 Department of Anaesthesia, Onze-Lieve-Vrouw Hospital, Aalst, Belgium

4 Department of Anaesthesiology and Intensive Care, Udayana University, Bali, Indonesia \& University of New South Wales, Kensington, NSW, Australia

5 Nuffield Department of Anaesthetics, Oxford University Hospital NHS Foundation Trust, Oxford, UK

\section{Introduction}

There is no firm consensus about how supraglottic airway devices (SADs) should be classified. One such classification, by Cook, designates a '1st generation' (e.g. LMA-Classic) incorporating a single breathing channel' and a '2nd generation incorporating separate breathing and gastric channels', as well as other design modifications mostly based around the dual channel model. These two 'generations' are widely accepted but the 3rd generation remains undefined [1-3].

In this article, we make the case for a '3rd generation' $\mathrm{SAD}$, which would have the added facility of 'correct placement under direct vision'. We conceptualize that this facility would be possible by incorporating cameras and fibreoptic illumination, but we do not wish to predefine any technical parameters. Our assertions are based on a theoretical notion, to make an intellectual case and thereby aim at encouraging future innovation. This proposed 3rd generation, hopefully, will attract the attention of product developers, researchers, clinicians and manufacturers into investigating actual needs of anaesthetists and other clinicians rather than concentrating on 'me too' copy-cat replicas of existing devices. 


\section{Ever-increasing indications of effective usage of SADs}

Roughly two decades after Brain's revolutionary introduction of the 'vintage' LMA-Classic [4], and more than six decades after the filing patent of its precursor (i.e. Leech's Pharyngeal Bulb Gasway) [5], Brain successfully launched the first prototype 2nd generation SADs, the 'LMA-ProSeal' [6], incorporating an airway tube with improved glottic seal and gastric drain tube channel for gastric decompression. Since then, SADs have become popular and highly effective devices in airway management [7]. The 2nd generation SAD is currently recommended over LMA-Classic or so called '1st generation tube-only airway device' [8-12].

The success of 2nd generation SADs is based on a set of near-ideal attributes as promulgated by Brimacombe [13] including a higher rate of successful first attempt placement with smoother insertion. There are two seals; one by the proximal cuff around the glottis, a second by the distal cuff sitting compactly into the oesophagus, resulting in higher oropharyngeal seal pressure compared with some precursor 'ventilation tube-only' SADs. The gastric tube channel allows passage of a gastric tube to vent gastric fluids whilst offering better protection from aspiration of regurgitated gastric contents. A bite block is incorporated to prevent obstruction of the airway, especially during emergence from anaesthesia. Finally, there is the option to intubate the trachea with the help of a flexible optical bronchoscope.

Beyond 'securing the airway', the applications of SADs have now widened to include use in the obese, other highrisk and specific populations in obstetric and paediatric anaesthesia and as an option using the SAD as a conduit to place a tracheal tube (TT), with or without fibreoptic assistance (e.g. LMA-Fastrach) [14]. Conversely, for some surgeries, the 'Bailey manoeuvre' can be used to exchange the TT at a deep plane of anaesthesia for an SAD, to facilitate smoother emergence, diminish cardiovascular stress responses, decrease respiratory complications and minimise coughing or straining [15-18]. The SAD is now recommended in resuscitation guidelines, especially as the primary airway device for airway management by nonanaesthesiologists [19]. SADs have established a foothold as rescue airway devices in 'Plan B' of difficult airway guidelines [8, 20-24]. Indeed, once the SAD is placed along this limb of the resuscitation 'tree' to rescue a failed intubation, removing it is to be regarded as a serious risk [21].

Special features of the 2nd generation SADs have well known advantages but they are also associated with hazards and required further modifications. Mask aperture bars (characteristic of 1st generation SADs) and epiglottiselevating bars (i.e. LMA-Fastrach) [25] became superfluous [26] and the newer SADs have no mask aperture bars [26]. Furthermore, SADs with 'floppy' distal cuffs can more easily fold over causing obstruction and the cuff was replaced by a reinforced tip $[27,28]$. Original 2 nd generation SADs had a very soft airway shaft crushable by teethclenching during emergence [29] and this led to incorporation of a bite block (e.g. LMA-ProSeal, LMA-Supreme, LMA-Protector, LMA-Gastro, i-gel,Ambu Aura-I, Ambu AuraGain, air-Q). Disposable SAD tubes and cuffs made of polyvinyl chloride (PVC) often created gaps and airway leaks, so PVC was replaced by more flexible, malleable and less traumatic silicone [30].

Despite myriad modifications and improvements to original design, several decades of operator experience and many manoeuvres to better adjust placement, the scientific literature is replete with reports of complications related to insertion and placement difficulties of the 2nd generation SADs, with multiple recommendations for avoiding those problems [13, 31-33]. Complications related to placement difficulties and inadequate sizing is irrespective of choice of brand and design SAD used, whether cuffed or non-cuffed [30].

An anatomically curved airway tube (e.g. LMA-Protector, i-gel) conforms better to the patient's anatomy. Larger airway and gastric drain tube channel diameters (e.g. LMAProtector, LMA-Gastro) enable insertion of wider-bore TTs and larger gastric tubes [34] as well as facilitating upper gastrointestinal endoscopy $[35,36]$.

\section{Why the need for SAD placement under direct vision?}

Although the 2nd generation SADs have many desirable features, they are, nevertheless, inserted in the same 'blind fashion' as the 1st generation devices, based on educated guesses about correct placement, appropriate device size and insertion depth. Clinicians still rely on a range of subjective indirect assessment and clinical tests (Table 1), dedicated to the simple task of correct placement of a single device [37-44]. This plethora of tests should alert clinicians that 'all is not well inside the camp'. In practice, very few of these techniques, i.e. auscultation, leakage test and fibreoptic examination, have enjoyed sustained clinical attention mostly because none of them allow corrective manoeuvres during the insertion process. Even if all clinical signs (appropriate capnogram and chest excursion, and absence of an audible leak at peak inspiratory pressures of $20 \mathrm{cmH}_{2} \mathrm{O}$ ) are reassuring, one cannot be certain that correct positioning has been achieved with 'blind' insertion techniques. Generally, it is hoped that cuff inflation with a standard volume, and/or manual palpation of the cuff, will automatically 


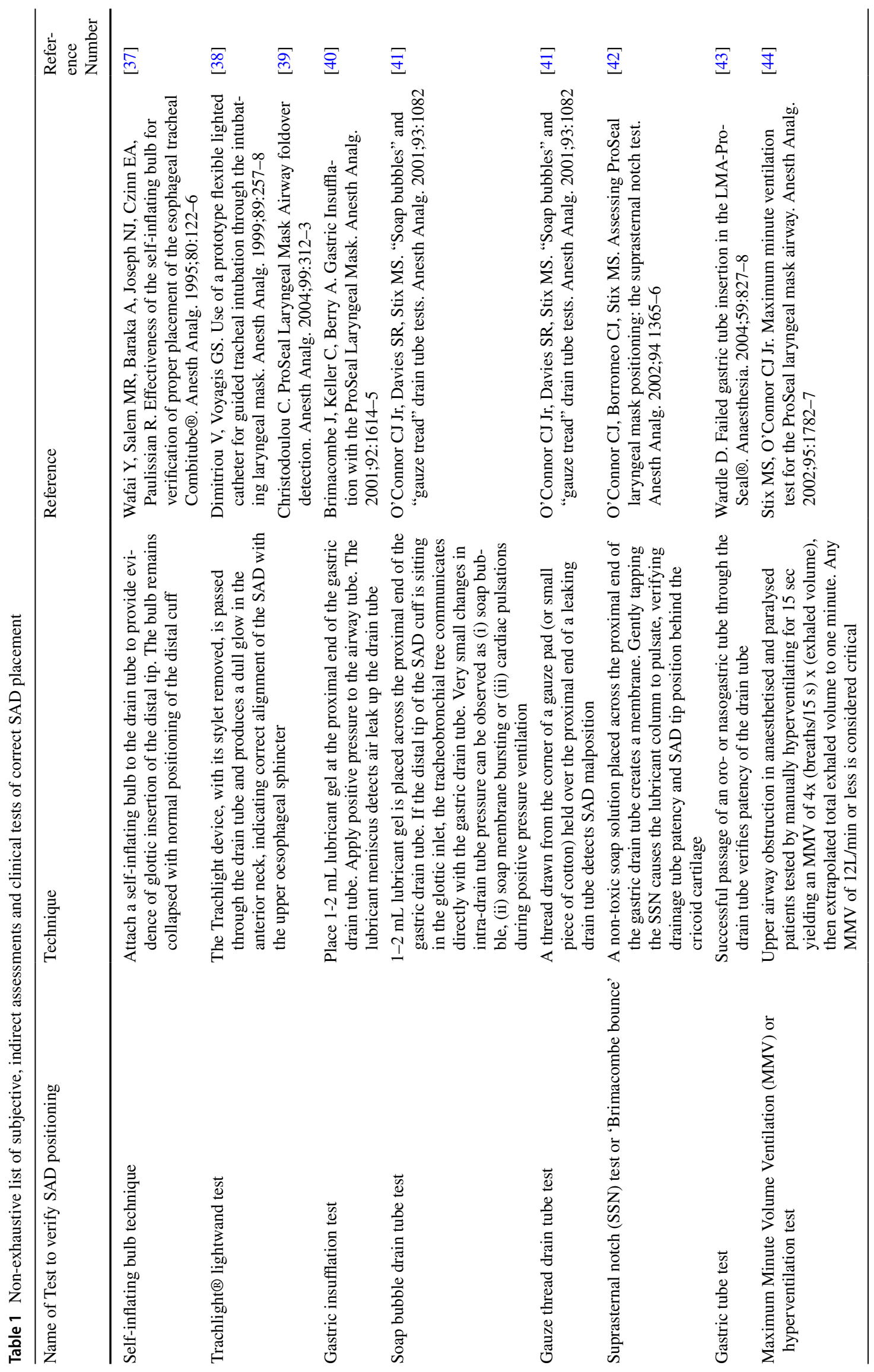


achieve an adequately sited SAD which will allow adequate gas exchange and protect against aspiration in patients with both easy and difficult airway anatomy. Yet, many studies (clinical, radiological, fibreoptic and ultrasound evaluations) consistently show that 50 to $80 \%$ of SADs, irrespective of make/brand and size, do not fit compactly in the designated anatomical position, which may, in turn, compromise safety [45-52].

A sub-optimally placed SAD can maintain an airway to some extent, but the device may be at increased risk for further displacement later during anaesthesia. Furthermore, malpositioning of SADs may potentially contribute to airway morbidity. Therefore, it is important to ensure optimal positioning of the SAD at the time of insertion of the device to provide adequate lung ventilation and eliminate these hazards.

A comparison of two studies adopting blind versus directvision SAD placement is instructive, especially when considering the upper limit of the $95 \%$ confidence intervals for the results, i.e. the 'worst that can happen' [53]. Zaballos et al. [54] recently conducted a multicentre, prospective, observational study in 280 non-paralysed patients with 'easy' airways. The then newly introduced LMA-Protector® (Teleflex ${ }^{\mathrm{TM}}$ Medical Europe, Westmead, Ireland) was inserted blind. The SAD size was changed in $8 \%$; additional insertion manoeuvres were used in the majority of cases (62\%); difficult/impossible gastric tube insertion arose in $28 \%$; and adequacy of ventilation was impaired in $23 \%$. Zaballos et al. [54] checked the position of the SAD fibrescopically, which suggested suitable placement in $66 \%$ by viewing the vocal cords and/or the posterior epiglottis. In a third of cases, malposition from downfolding of the epiglottis into the bowl of the device, airway obstruction, low oropharyngeal leak pressure (range $14-40 \mathrm{cmH}_{2} \mathrm{O}$ ), hypoxia or gastric insufflation occurred. These results are not surprising and have been reported across many SADs [30, 55, 56]. In contrast, Van Zundert et al. placed the same device (LMA-Protector®) using an 'insert-detect-correct-as-yougo-insertion-technique' and noticed similar shortcomings of SADs during insertion but, at least, this technique allowed immediate corrective measures/manoeuvres, resulting in better positioning with $94 \%$ achieving Grade I fibreoptic inspection, allowing superior gas exchange and requiring no further corrective measures during the maintenance phase of anaesthesia [34].

\section{Is it time to abandon blind insertion of SADs?}

Clinicians usually select SAD size based on manufacturer's instructions, yet many devices do not result in a good airway seal and require corrective re-sizing. Besides, size instructions for broadly similar devices differ across manufacturers. Often, clinicians choose SAD size based on weight, height, gender and anatomical parameters but failure may ensue in inadequate seal due to improper size selection and abnormal oropharyngeal anatomy (i.e., size per se is not the only factor).

We have previously proposed a flow chart to identify and correct the problem of incorrectly positioned, blindly inserted SADs $[30,55]$. If the SAD is too small, sits too deeply or is inflated inappropriately, it may result in air leaks as well as obstruct the airway. If the SAD is too big, sits too superficially or is hyperinflated, it may not produce an adequate seal. A subluxated SAD may result in potential loss of airway. Real-time, vision-guided insertion of SADs can easily confirm adequacy of chosen size and allow immediate correction of any malposition secondary to incorrect sizing, incorrect cuff inflation or incorrect insertion technique.

The oropharyngeal leak pressure (OLP; the pressure that breaks the seal between the SAD cuff and the peri-cuff mucosa) is often used as a surrogate measure of correct device positioning, with $>25 \mathrm{cmH}_{2} \mathrm{O}$ recommended [57, 58]. However, without prior verification of correct device positioning in the hypopharynx, the OLP has little meaning because inflation techniques differ substantially and there is a lack of uniform guidelines [59]. Manual palpation of the cuff, listening to the disappearance of an audible air leak or injection of a standard volume of air into the cuff via the pilot balloon may either result in cuff hypoinflation (which may increase the risk of aspiration of gastric contents due to an incomplete seal) or cuff hyperinflation (with airway and oral tissue trauma potentially resulting in sore throat, airway damage, nerve palsy and aspiration risk from gastro-oesophageal reflux) [60]. Cuff manometers, including built-in pressure indicator devices, have been designed to allow quantification and adjustment of intracuff pressure to the $40-60 \mathrm{cmH}_{2} \mathrm{O}$ standard and eliminate gross under- and over-inflation.

\section{Is there now a need for a 3rd generation, direct vision-guided SAD?}

It has been confirmed that SADs placed under direct vision are safer and more effective [30] and this broadening body of evidence is the driver for the development of 3rd generation SADs which would facilitate the placement under direct vision (inspection). This concept follows and parallels the natural history progression of endotracheal (TT) placement. Blind (e.g. nasal) tracheal intubation is not performed any more (and has been criticized in the UK Difficult Airway Society's guidelines) [8,21-24]. The traditional method of double lumen tube placement has changed to video assisted placement such that fibreoptic checking of placement has 
been rendered redundant [61]. A fundamental question for the anaesthesia community is whether we should now emulate this evolution and incorporate routine video facilities into SADs.

Perhaps, the main barrier to be anticipated to such a dramatic improvement is the infrequent incidence of serious misadventure; 2nd (and, indeed, 1st) generation SADs are generally 'forgiving' of suboptimal placement. Perhaps all that is noticed is some 'noisy breathing'.

We believe that the driver for change will come, not from the bulk of everyday practitioners but from a small minority of pioneers who insist upon progressive, sequential quality improvement in all areas of practice. A parallel example may include the now almost defunct practice of placing central venous catheters or peripheral nerve blocks blindly; such practice is now virtually unthinkable, with direct (ultrasound) vision techniques embedded in guidelines [62-65]. We would like to make the case, that, in future, blind insertion of SAD will no longer be acceptable once direct-vision SADs become available.

Direct vision 3rd generation SADs allows for a more informed guidance for the airway pathway while avoiding structures that might be damaged by the device. Most importantly, continual visualisation permits direct, immediate, pari passu, execute-as-you-advance corrective manoeuvres.

The recent SARS 2 beta-coronavirus COVID-19 pandemic has implications for airway management [66-68]. The key advice to protect the anaesthesiologist is to ensure high first-time success while keeping distance when viewing the oral cavity/larynx. This is best achieved with a videolaryngoscope and avoidance of bag mask ventilation [68]. In a similar vein, an SAD offering direct vision could be theoretically better placed, without manoeuvres that might create infectious air droplets, at increased COVID-19 anaesthetist-patient distancing and minimise the need for mask ventilation in between attempts.' Airway management recommendations, associated with the current ongoing COVID19 pandemic exhorting anaesthesiologists to use the videolaryngoscope to protect the intubator from disease exposure, highlights even further the need for safer direct-vision 3rd generation SADs much as we are proposing.

\section{Desirable components of a 3rd generation SAD}

Ideally, the proposed 3rd generation SADs should incorporate real-time evaluation of the airway device during insertion allowing immediate corrective manoeuvres if needed. This may be realised by using internal and external visualisation with three lightweight, camera-LED bundles, running via one external cable to a bayonet port for access to a light source and a monitor partitioned into three displays.
Provision of three cameras may be sufficient to detect correct seals and alignment of the tip of the epiglottis and visualise the rim of the proximal cuff. Ideally, one camera can be placed at the distal drain to view distal tip entry into the oesophagus; a second allowing inspection through the ventilation tube; and a third to inspect alignment of the proximal cuff with the tip of the epiglottis and verify correct SAD size selection. This is akin to the parking assistance incorporated into many modern cars which have many more than three cameras. Inexpensive miniaturisation puts such innovation within our grasp and fitting such cameras based on the same principles as for modern naso-endoscopes is a distinct possibility. We believe that both the technology and the market already exist; all that now remains is the resolve and will of current manufacturers to produce the proposed advanced 3rd generation SAD.

We recognize that previous attempts at introducing a video-assisted SAD in the LMA-CTrach and TotalTrack videolaryngeal mask $[7,69,70]$ were primarily designed to assist orotracheal intubation rather than using the camera to achieve optimal positioning of the SAD. The size and position of the LMA-CTrach screen made the device unwieldy, so our proposition of a video-guided SAD would require either a remote or detachable screen, similar to the Videotrack [70] or compatibility with our standard video monitors in operating theatres or mobile cell-phones with telemetry or single cable linkage. Miniaturisation of cameras, fibreoptics cabling, high performance LED lighting and WiFi linkage of device and monitoring make our proposal eminently realisable.

In principle, a vision-guided SAD will overcome most, if not all, of the difficulties of malposition and misplacement with all the attendant sequelae. Third generation SADs would obtain better anatomical fit and optimal functional results during airway management. The understanding is that new device design, implementation and evaluation will require further evidence-based research proof in order to ascertain with certitude whether the novel design features produce improved patient safety and warrant the 3rd generation nomenclature.

The proposed development of the 3rd generation SAD is expected to meet objections and concerns from many quarters. An average clinician may not see the immediate benefit in routine clinical practice especially if increased cost becomes an issue. One can expect that, as for any new development introduced into clinical practice, initial cost of the SAD will be higher, but the component parts are themselves ubiquitous, inexpensive and readily accessible. Over a short period of time, especially given the enormous usage volume which SADs enjoy, the cost will decrease and such projects would rapidly become financially viable in routine practice especially if it can be proven that insertion of SADs is made safer and more effective. 


\section{Conclusions}

In summary, established deficiencies of blind insertion lead us to conclude that there are potential advantages for advocating the case for 3rd generation, direct-vision SAD devices. While some interventions can help correct or mitigate against a sub-optimally placed SAD, the ideal solution is a family of 3rd generation, vision-guided devices. Just as we anticipate videolaryngoscopes to be the standard or default for tracheal intubation, as already exists in many advanced centres, we hope and dream that clinicians will accept and embrace the notion that this innovation, an SAD sited routinely under direct-vision, will become the everyday norm within the scope of practice.

Funding This study was supported by departmental resources only.

\section{Compliance with ethical standards}

Conflict of interest The authors declare no funding or conflicts of interest. TVZ is Associate Editor of JCMC.

Ethical approval Not applicable.

Informed consent Not applicable.

Provenance of Supraglottic Airway Devices (SADs) used in this article:

LMA-Classic $® ;$ LMA-ProSeal ${ }^{\circledR}$; LMA-Supreme ${ }^{\circledR}$; LMA-Protector ${ }^{\circledR}$; LMA-Gastro®, all from Teleflex ${ }^{\mathrm{TM}}$ Medical Europe, Westmead, Ireland.

i-gel®, Intersurgical Ltd, Crane House, Molly Millars Lane, Wokingham, Berkshire, RG41 2RZ, UK

Ambu Aura-I®, Ambu AuraGain ${ }^{\circledR}$, from Ambu A/S, Baltorpbakken 13, DK-2750 Ballerup, Denmark

Air-Q ${ }^{\circledR}$, The Air-Q ${ }^{\circledR}$ Intubating Laryngeal Airway ILA ${ }^{\mathrm{TM}}$, Cookgas ${ }^{\circledR}$ LLC, Mercury Medical, Clearwater, FL, USA

TotalTrack® VLM (Video Laryngeal Mask), Medcom Flow®, Viladecans, Barcelona, Spain

\section{References}

1. Cook TM. Third generation supraglottic airway devices: an undefined concept and misused term. Time for an updated classification of supraglottic airway devices. Br J Anaesth. 2015;115:633.

2. Miller DM. Third generation supraglottic airways: is a new classification needed? Br J Anaesth. 2015;115:634.

3. Goyal R. Third generation has not arrived yet. Br J Anaesth. 2015;115:635.

4. Brain AIJ. The laryngeal mask - a new concept in airway management. Br J Anaesth. 1983;55:801-5.

5. Avery EC. The Leech airway: precursor to the modern supraglottic airway. Can J Anaesth. 2018;65:586-7.

6. Brain AIJ, Verghese C, Strube PJ. The LMA-ProSeala laryngeal mask with an oesophageal vent. Br J Anaesth. 2000;84:650-4.
7. Van Zundert TC, Brimacombe JR, Ferson DZ, Bacon DR, Wilkinson DJ. Archie brain: celebrating 30 years of development in laryngeal mask airways. Anaesthesia. 2012;67:1375-85.

8. Higgs A, McGrath BA, Goddard C, et al. Guidelines for the management of tracheal intubation in critically ill adults. $\mathrm{Br} \mathrm{J}$ Anaesth. 2018;120:323-52.

9. 4th National Audit Project of The Royal College of Anaesthetists and The Difficult Airway Society. Major complications of airway management in the United Kingdom, Report and Findings. Royal College of Anaesthetists, London. 2011. https://www.rcoa.ac.uk/ sites/default/files/documents/2019-09/NAP4\%2520Full\%2520R eport.pdf. Accessed 15 Jan 2020.

10. Cook TM, Kelly FE. Time to abandon the 'vintage' laryngeal mask airway and adopt second-generation supraglottic airway devices as first choice. Br J Anaesth. 2015;115:497-9.

11. Higgs A, McGrath BA, Goddard C, et al. DAS guidelines on the airway management of critically ill patients. Anaesthesia. 2018;73:1035-6.

12. Pandit JJ, Irwin MG. Airway management in critical illness: practice implications of new Difficult Airway Society guidelines. Anaesthesia. 2018;73:544-8.

13. Brimacombe JR. Laryngeal mask anesthesia—principles and practice. 2nd ed. London, UK: Saunders; 2005.

14. Danha RF, Thompson JL, Popat MT, Pandit JJ. Comparison of fibreoptic-guided orotracheal intubation through classic and single-use laryngeal mask airways. Anaesthesia. 2005;60:184-8.

15. Nair I, Bailey PM. Use of the laryngeal mask for airway maintenance following tracheal extubation. Anaesthesia. 1995;50:174-5.

16. Sorbello M, Cortese G, Gaçonnet C, Skinner M. A modified Bailey's manoeuvre for supraglottic airway continuum using LMA Protector $^{\mathrm{TM}}$. Indian J Anaesth. 2019;63:78-80.

17. Tanoubi I, Sun JN, Drolet P, Fortier LP, Donati F. Replacing a double-lumen tube with a single-lumen tube or a laryngeal mask airway device to reduce coughing at emergence after thoracic surgery: a randomized controlled single-blind trial. Can J Anesth. 2015;62:988-95.

18. Suppiah RK, Rajan S, Paul J, Kumar L. Respiratory and hemodynamic outcomes following exchange extubation with laryngeal mask airway as compared to traditional awake extubation. Anesth Essays Res. 2016;10:212-7.

19. Länkimäki S, Alahuhta S, Silfvast T, Kurola J. Feasability of LMA Supreme for airway management in unconscious patients by ALS paramedics. Scand J Trauma, Resus Emerg Med. 2015;23:24.

20. Frerk C, Mitchell VS, McNarry AF, et al. Difficult Airway Society 2015 guidelines for management of unanticipated difficult intubation in adults. Br J Anaesth. 2015;115:827-48.

21. Marshall SD, Pandit JJ. Radical evolution: the 2015 Difficult Airway Society guidelines for managing unanticipated difficult or failed tracheal intubation. Anaesthesia. 2016;71:131-7.

22. Mushambi MC, Kinsella SM, Popat M, et al. Obstetric Anaesthetists'Association and Difficult Airway Society guidelines for the management of difficult and failed tracheal intubation in obstetrics. Anaesthesia. 2015;70:1286-306. https://doi. org/10.1111/anae.13260.

23. Apfelbaum JL, Hagberg CA, Caplan RA, et al. Committee on standards and practice parameters. Practice guidelines for management of the difficult airway: an updated Report by the American Society of Anesthesiologists task force on management of the difficult airway. Anesthesiology. 2013;118:251-70.

24. Batuwitage B, Charters P. Postoperative management of the difficult airway. Br J Anaesth Educ. 2017;17:235-41.

25. Panjwani S, Seymour P, Pandit JJ. A manoeuvre for using the flexible fibreoptic bronchoscope through the Intubating Laryngeal Mask Airway. Anaesthesia. 2001;56:696-7.

26. Van Zundert TC, Hendrickx JF, De Witte JL, Wong DT, Cattano $\mathrm{D}$, Brimacombe JR. Do mask aperture bars of extraglottic airway 
devices prevent prolapse of epiglottis causing airway obstruction? A randomized crossover trial in anesthetized adult patients. J Clin Anesth. 2016;31:231-7.

27. Cook T, Howes B. Supraglottic airway devices: recent advances. Cont Educ Anaesthesia, Critical Care \& Pain. 2011;11:56-61.

28. Rosenberg MB, Phero JC, Becker DE. Essentials of airway management, oxygenation and ventilation: part 2: advanced airway devices: supraglottic airways. Anesth Prog. 2014;61:113-8.

29. Verghese C, Mena G, Ferson DZ, Brain AIJ. Laryngeal mask airway. In: Hagberg CA, editor. Benumof and Hagberg's Airway Management. 4th ed. Philadelphia: Elsevier Saunders; 2017. p. 470.

30. Van Zundert AA, Kumar CM, Van Zundert TC. Malpositioning of supraglottic airway devices: preventive and corrective strategies. Br J Anaesth. 2016;116:579-82.

31. Kwanten LE, Madhivathanan P. Supraglottic airway devices: current and future uses. Br J Hosp Med (Lond). 2018;79:31-5. https ://doi.org/10.12968/hmed.2018.79.1.31.

32. Gordon J, Cooper RM, Parotto M. Supraglottic airway devices: indications, contraindications and management. Minerva Anestesiol. 2018;84:389-97. https://doi.org/10.23736/S0375 $-9393.17 .12112-7$.

33. Michalek P, Donaldson W, Vobrubova E, Hakl M. Complications associated with the use of supraglottic airway devices in perioperative medicine. Biomed Res Int. 2015;2015:746560. https://doi. org/10.1155/2015/746560.

34. Van Zundert AAJ, Wyssusek KH, Pelecanos A, Roets M, Kumar $\mathrm{CM}$. A prospective randomized comparison of airway seal using the novel vision-guided insertion of LMA-Supreme $®$ and LMAProtector®. J Clin Monit Comput. 2019. https://doi.org/10.1007/ s10877-019-00301-3.

35. Terblanche NCS, Middleton C, Choi-Lundberg DL, Skinner M. Efficacy of a new dual channel laryngeal mask airway, the LMA®-Gastro ${ }^{\mathrm{TM}}$ Airway, for upper gastrointestinal endoscopy: a prospective observational study. Br J Anaesth. 2018;120:353-60.

36. Kuzhively J, Pandit JJ. Anesthesia and airway management for gastrointestinal endoscopic procedures outside the operating room. Curr Opin Anesthesiol. 2019;32:517-22.

37. Wafai Y, Salem MR, Baraka A, Joseph NJ, Czinn EA, Paulissian R. Effectiveness of the self-inflating bulb for verification of proper placement of the esophageal tracheal Combitube ${ }^{\circledR}$. Anesth Analg. 1995;80:122-6.

38. Dimitriou V, Voyagis GS. Use of a prototype flexible lighted catheter for guided tracheal intubation through the intubating laryngeal mask. Anesth Analg. 1999;89:257-8.

39. Christodoulou C. ProSeal Laryngeal Mask Airway foldover detection. Anesth Analg. 2004;99:12-3.

40. Brimacombe J, Keller C, Berry A, Mitchell S. Assessing ProSeal laryngeal mask positioning: the suprasternal notch test. Anesth Analg. 2002;94:1366.

41. O'Connor CJ, Borromeo CJ, Stix MS. Assessing ProSeal laryngeal mask positioning: the suprasternal notch test. Anesth Analg. 2002;94:1365-6.

42. O'Connor CJ Jr, Davies SR, Stix MS. "Soap bubbles" and "gauze tread" drain tube tests. Anesth Analg. 2001;93:1082.

43. Wardle D. Failed gastric tube insertion in the LMA-ProSeal®. Anaesthesia. 2004;59:827-8.

44. Stix MS, O'Connor CJ Jr. Maximum minute ventilation test for the ProSeal laryngeal mask airway. Anesth Analg. 2002;95:1782-7.

45. Shorten GD, Opie NJ, Graziotti P, Morris I, Khangure M. Assessment of upper airway anatomy in awake sedated and anaesthetized patients using magnetic resonance imaging. Anaesth Intensive Care. 1994;22:165-9.

46. Brimacombe JR. Laryngeal Mask Anesthesia - Principles and Practice. 2nd ed. Philadelphia: Saunders; 2005. p. 97-9.
47. Aoyama K, Takenaka I, Sata T, Shigematsu A. The triple airway manoeuvre for insertion of the laryngeal mask airway in paralyzed patients. Can J Anaesth. 1995;42:1010-6.

48. Moustafa MA, Abdelhady MM. Fiberoptic assessment of the laryngeal mask airway (LarySeal) position after one hour of positive pressure ventilation: an observational study. J Clin Anesth. 2014;26:480-4.

49. Joshi S, Sciacca RR, Solanki DR, Young WL, Mathru MM. A prospective evaluation of clinical tests for placement of laryngeal mask airways. Anesthesiology. 1998;89:1141-6.

50. Payne J. The use of the fibreoptic laryngoscope to confirm the position of the laryngeal mask. Anaesthesia. 1989;44:865.

51. Song K, Yi J, Liu W, Huang S, Huang Y. Confirmation of laryngeal mask airway placement by ultrasound examination: a pilot study. J Clin Anesth. 2016;34:638-46.

52. Kim J, Kim JY, Kim WO, Kil HK. An ultrasound evaluation of laryngeal mask airway position in pediatric patients: an observational study. Anesth Analg. 2015;120:427-32.

53. Pandit JJ. If it hasn't failed, does it work? On 'the worst we can expect' from observational trial results, with reference to airway management devices. Anaesthesia. 2012;67:578-83.

54. Zaballos M, Zaballos J, López S, et al. The LMA® ProtectorTM in anaesthetised, non-paralysed patients: a multicentre prospective observational study. Anaesthesia. 2019;74:333-9.

55. Van Zundert AAJ, Gatt SP, Kumar CM, Van Zundert TCRV, Pandit JJ. 'Failed supraglottic airway': an algorithm for suboptimally placed supraglottic airway devices based on videolaryngoscopy. Br J Anaesth. 2017;118:645-9.

56. Van Zundert AAJ, Gatt SP, Kumar CM, Van Zundert TCRV. Vision-guided placement of supraglottic airway device prevents airway obstruction: a prospective audit. Br J Anaesth. 2017;118:462-3.

57. Brain AIJ. Pressure in laryngeal mask airway cuffs. Anaesthesia. 1996;51:603.

58. Wong DT, Tam AD, Mehta V, Raveendran R, Riad W, Chung FF. New supraglottic airway with built-in pressure indicator decreases postoperative pharyngolaryngeal symptoms: a randomized controlled trial. Can J Anaesth. 2013;60:1197-203.

59. Checketts MR, Alladi R, Ferguson K, et al. Recommendations for standards of monitoring during anaesthesia and recovery 2015: Association of Anaesthetists of Great Britain and Ireland. Anaesthesia. 2016;71:85-93.

60. Hensel M, Schmidbauer W, Geppert D, Sehner S, Bogush G, Kerner T. Overinflation of the cuff and pressure on the neck reduce the preventive effect of supraglottic airways on pulmonary aspiration: an experimental study in human cadavers. Br J Anaesth. 2016;116:289-94.

61. Heir JS, Guo SL, Purugganan R, et al. A randomized controlled study of the use of video double-lumen endobronchial tubes versus double-lumen endobronchial tubes in thoracic surgery. J Cardiothorac Vasc Anesth. 2018;32:267-74.

62. Apfelbaum JL, Rupp SM, Tung A, Connis RT, Grant MD, Practice MJB. Guidelines for Central Venous Access 2020. An updated report by the American Society of Anesthesiologists Task Force on Central Venous Access. Anesthesiology. 2020;2020(132):8-43.

63. Lewis SR, Price A, Walker KJ, et al. Ultrasound guidance for upper and lower limb blocks. Cochrane Database Syst Rev. 2015;9:CD006459.

64. Sites BD, Chan VW, Neal JM, et al. The American Society of Regional Anesthesia and Pain Medicine and the European Society of Regional Anaesthesia and Pain Therapy Joint Committee Recommendations for education and training in ultrasound-guided regional anesthesia. Reg Anesth Pain Med. 2010;35:S74-80.

65. ANZCA Guidelines for the Management of Major Regional Analgesia, PS03. 2014. https://www.anzca.edu.au/documents/ 
ps03-2014-guidelines-for-the-management-of-major-r. Accessed 27 Feb 2020.

66. Wax RS, Christian MD. Practical recommendations for critical care and anesthesiology teams caring for novel coronavirus (2019nCoV) patients. Can J Anesth. 2020. https://doi.org/10.1007/ s12630-020-01591-x.

67. Peng PWH, Ho P-L, Hota SS. Outbreak of a new coronavirus: what anaesthetists should know. Br J Anaesth. 2020;124:497-501. https://doi.org/10.1016/j.bja.2020.02.008.

68. Ti LK, Ang LS, Foong TW, Ng BSW. What we do when a COVID-19 patient needs an operation: operating room preparation and guidance. Can J Anesth. 2020. https://doi.org/10.1007/ s12630-020-01617-4.
69. Liu EHC, Goy RWL, Chen FG. The LMA CTrach ${ }^{\mathrm{TM}}$, a new laryngeal mask airway for endotracheal intubation under vision: evaluation in 100 patients. Br J Anaesth. 2006;96:396-400

70. Gomez-Rios MA, Freire-Vila E, Vizcaino-Martinez L, EstevezGonzalez E. The Totaltrack: an initial evaluation. Br J Anaesth. 2015;115:798-9.

Publisher's Note Springer Nature remains neutral with regard to jurisdictional claims in published maps and institutional affiliations. 